\title{
Infecciones bacterianas desatendidas en pacientes con COVID-19
}

\author{
Neglected bacterial infections in COVID-19 patients
}

\author{
Adrián Martínez-Meléndez, ${ }^{1}$ Elvira Garza-González, ${ }^{2}$ Rayo Morfín-Otero ${ }^{3}$ y Flora Cruz-López * \\ ${ }^{1}$ Facultad de Ciencias Químicas, Universidad Autónoma de Nuevo León, Monterrey, Nuevo León; ${ }^{2}$ Facultad de Medicina, Universidad Autónoma \\ de Nuevo León, Monterrey, Nuevo León; ${ }^{3}$ Universidad de Guadalajara, Hospital Civil de Guadalajara "Fray Antonio Alcalde", Guadalajara, Jalisco. \\ México
}

COVID-19 es una enfermedad causada por el coronavirus SARS-CoV-2. Para septiembre de 2021, en México se habían registrado más de 3.3 millones de casos y 261000 muertes (https://coronavirus.jhu.edu/ region/mexico). El sistema de salud se ha visto rebasado desde el inicio de la pandemia debido a la elevada transmisión del virus. Aproximadamente $25 \%$ de los pacientes hospitalizados con una forma grave de COVID-19 ingresó a unidades de cuidados intensivos (UCl) y $31 \%$ de ellos requirió ventilación mecánica. ${ }^{1}$

Aun cuando el uso de ventilación mecánica y la estancia prolongada en la $\mathrm{UCl}$ (de siete a 14 días en pacientes con COVID-19) son factores de riesgo para el desarrollo de neumonía hospitalaria, ${ }^{2}$ existen pocos informes sobre coinfecciones bacterianas en pacientes con COVID-19 en México. Se ha descrito el desarrollo de infecciones bacterianas hasta en $16 \%$ de los pacientes con COVID-19 en la UCl, ${ }^{3}$ incluyendo infecciones por Acinetobacter baumannii resistente a carbapenémicos, Escherichia coli, Pseudomonas aeruginosa y Enterococcus spp.

Es posible que las coinfecciones por bacterias y SARS-CoV-2 no se estén monitoreando durante la pandemia debido a que los trabajadores de la salud están enfocados en las complicaciones de COVID-19 y en las medidas de contención para prevenir la propagación del virus en los hospitales. Este escenario es desconcertante y debe ser atendido con urgencia ante el aumento de las tasas de mortalidad por coinfecciones bacterianas en pacientes de la $\mathrm{UCl}$ de hospitales mexicanos. Debemos evitar no solo la propagación del virus en las áreas hospitalarias, sino también reforzar las medidas para prevenir el desarrollo de coinfecciones bacterianas y disminuir la mortalidad en los pacientes con COVID-19.

\section{Bibliografía}

1. Zhou F, Yu T, Du R, Fan G, Liu Y, Liu Z, et al. Clinical course and risk factors for mortality of adult inpatients with COVID-19 in Wuhan, China: a retrospective cohort study. Lancet. 2020;395(10229):1054-1062.

2. Docherty $A B$, Harrison EM, Green CA, Hardwick HE, Pius R, Norman L, et al. Features of 20133 UK patients in hospital with covid-19 using the ISARIC WHO Clinical Characterisation Protocol: prospective observational cohort study. BMJ. 2020;369:m1985.

3. Ñamendys-Silva SA, Alvarado-Ávila PE, Domínguez-Cherit G, Rivero-Sigarroa E, Sánchez-Hurtado LA, Gutiérrez-Villaseñor A, et al. Outcomes of patients with COVID-19 in the intensive care unit in Mexico: A multicenter observational study. Heart Lung. 2021;50(1):28-32.

\footnotetext{
Correspondencia:

Fecha de recepción: 03-09-2021

*Flora Cruz-López

Fecha de aceptación: 21-09-2021

Gac Med Mex. 2022;158:66

E-mail: flora.cruz@live.com

DOI: $10.24875 / G M M .21000564$

Disponible en PubMed

0016-3813/@ 2021 Academia Nacional de Medicina de México, A.C. Publicado por Permanyer. Este es un artículo open access bajo la licencia CC BY-NC-ND (http://creativecommons.org/licenses/by-nc-nd/4.0/).
} 